\title{
Effectiveness of Designed Educational Programme for Nurse's Regarding Using the Braden Scale to Predict Pressure Ulcer Risk
}

\author{
Shereen Ahmed Ahmed Qalawa, Amal Bakr Abo El - Ata \\ Department of Medical -Surgical Nursing, Faculty of Nursing, Port-said University, Port-Said, Egypt \\ Email address: \\ shereen.q066@yahoo.com (S. A. A. Qalawa), amelsarwat@yahoo.com (A. B. A. El - Ata)
}

\section{To cite this article:}

Shereen Ahmed Ahmed Qalawa, Amal Bakr Abo El - Ata. Effectiveness of Designed Educational Programme for Nurse's Regarding Using the Braden Scale to Predict Pressure Ulcer Risk. American Journal of Nursing Science. Vol. 5, No. 1, 2016, pp. 1-7. doi: 10.11648/j.ajns.20160501.11

\begin{abstract}
Introduction: Pressure ulcer prevention and management is an important approach of basic nursing care. Pressure sores affect people who are unable to change position regularly. Sustained pressure on those areas which support the body leads to reduced blood supply and eventually death of the skin and underlying muscles (a pressure sore). Aim: This study was conducted to evaluate the effectiveness of designed educational programme for nurse's regarding using the Braden Scale to Predict Pressure Ulcer Risk. Subjects and method: A quasi- experimental research design was used. Convenience samplings were selected from available nurses worked in the selected setting as following and met selected criteria. It included 99 nurse in port said city at governmental hospitals from ICU and CCU, orthopedics, and medical units at pot said general hospital, Elzohour, Port-fouad hospitals. Data were collected through using one tool contains 3 main parts developed by the researchers based on literature review \& modificated tool from Registered Nurses' Association of Ontario (2006) and Ayello, 2004 as follows: Part I: includes Sociodemographic data of nurses; Part II: includes nurse's knowledge regarding Braden scale and Part III: contains Observational checklist in using Braden scale. Results: The study revealeda highly statistically significant difference were found between pre educational programme phase and post educational programme phase in relation to nurse's total scores of knowledge and practice of Braden scale as a predictive risk assessment of pressure ulcer. Conclusion \& recommendations: The present study concluded that there are obvious needs for educational programme to increase nurse's awareness of Braden Scale as predictive risk assessment of pressure ulcer.
\end{abstract}

Keywords: Effectiveness, Designed, Educational Programme, Nurses, Braden Scale, Pressure Ulcer, Risk

\section{Introduction}

A pressure ulcer is any lesion on the skin caused by unrelieved pressure and resulting in damage to underlying tissue. Pressure ulcer occurs commonly in areas subjected to high pressure from body weight on bony prominences. Pressure ulcer also called as decubitus ulcers. The word decubitus comes from Latin which means to lie-down. Pressure ulcer develops when soft issue (skin, subcutaneous tissue and muscle) are compressed between a bony prominence and a firm surface for a prolonged period of time. Therefore, immobility and inactivity is a major risk factor for developing pressure ulcer more than $95 \%$ of all pressure ulcers occur over a bony prominence only. (Hussain, 2009)

All patients are potentially at risk of developing a pressure ulcer. However, they are more likely to occur in people who are seriously ill, have a neurological condition, impaired mobility, impaired nutrition, or poor posture or a deformity. Also, the use of equipment such as seating or beds which are not specifically designed to provide pressure relief, can cause pressure ulcers. As pressure ulcers can arise in a number of ways, interventions for prevention and treatment need to be applicable across a wide range of settings including community and secondary care. This may require organizational and individual change and a commitment to effective delivery. (National institute for health and care excellence, 2014)

By 2006, the overall incidences of pressure sores for hospitalized patients' ranges from $2.7 \%$ to $29.5 \%$, greater than $50 \%$ has been reported for patients in critical care settings. In India (2004), the prevalence rate of pressure 
ulcers reported in various studies ranging from $4.7 \%$ to $18.6 \%$. $4.1 \%$ to $29.7 \%$ of patients who are staying at home suffered from pressure ulcers. In UK, its estimated that between $4 \%$ and $10 \%$ of all patients admitted to hospitals will develop at least one pressure ulcers. For elderly person with mobility problems, the figure can be as high as $70 \%$. In Houstan (2004), The Memorial Hermann South West Hospital noted a $12 \%$ incidence in hospital acquired pressure ulcers, a rate that is above the $7 \%$ national average.

The basic nursing care deals with many nursing procedures are Prevention and management of pressure sores. Pressure sores affect people who are unable to change position regularly. Sustained pressure on those areas which support the body leads to reduced blood supply and eventually death of the skin and underlying muscles (a pressure sore).Pressure ulcers are typically located in areas such as heels, elbows, shoulders and the sacral region and are graded or staged to classify the degree of tissue damage.(Thomas, 2009)

The Braden scale for predicting pressure sore risk was first introduced in 1987. It is a summated rating scale composed of six subscales: sensory perception, mobility, activity, moisture, nutrition, and friction and shear. The six subscales are rated from 1 to 4 (Except friction and shear, which rates from 1-3). A total score range of 6 to 23 is possible, and the lower the score, the higher the risk for pressure sore development. The critical cutoff score for high risk is16. An admission Braden score used for risk assessment is predictive of pressure sore development but not as predictive as the assessment made 48 to 72 hours after admission. Braden also recommends that the interval and frequency of risk assessment be determined according to the stability of the patient population. The Braden scale has been extensively tested in adult clinical areas. (Gordon et al, 2004)

Thus, Prevention is in many ways better than protection due to the fact that perfect Protection is impossible. This fact has become well known by the observation that there is always something that potentially can go wrong. In order to ensure safety by preventing something from happening, i.e. eliminating risks, it is first of all necessary that the risks are known or can be made known. (Vangberg, 2008). In addition to, the cost of pressure ulcer treatment is much greater than the cost of prevention. Treating a pressure ulcer incurs considerable cost to the patient and hospital, especially if the pressure ulcer has advanced beyond stage one. (Hussain, 2009)

\subsection{Significance of Study}

Lack of knowledge about pressure ulcers can be costly to health care institutions and fatal to patients if not properly treated. The treatment of pressure ulcers can be very complicated for nursing staff. Lead to worsening wounds, increase cost, and death if wound healing is prolonged. Caring for patients with pressure ulcers has revealed proven results of a failing healthcare system nationally (Smith, 2014).

Aim of the study: The study was conducted to evaluate the effectiveness of designed educational programme for nurses' regarding using the Braden Scale to predict pressure ulcer risk through:
- Assessing nurses' knowledge regarding using the Braden Scale to Predict Pressure Ulcer Risk.

- Assessing nurses' practice regarding using the Braden Scale to Predict Pressure Ulcer Risk.

- Developing educational programme for nurse's regarding using the Braden Scale to Predict Pressure Ulcer Risk.

- Implementing educational programme for nurses' regarding using the Braden Scale to Predict Pressure Ulcer Risk.

- Evaluating the effectiveness of implementing educational programme on nurses performance regarding using the Braden Scale to Predict Pressure Ulcer Risk.

\subsection{Research Hypotheses}

To fulfill the aim of the study, the following research hypotheses were tested:

H1: The mean post-test total knowledge score among nurses will be significantly higher than pre-test total knowledge score.

H2: The mean post-test practice score among nurses will be significantly higher than pre-test score regarding applying Braden scale.

\section{Subjects and Method}

A quasi-experimental research study research design was utilized in this study; the study will be portrayed under the four main designs as follows:

1. Technical Design.

2. Operational Design.

3. Administrative design.

4. Statistical Design.

(1)Technical Design:

The technical designs for this study included research setting, subjects, tools and methods of data collection.

A. Study Setting:

This study was carried out in port-said city at ministry of health hospitals that include burn, orthopedics, medical units at port said general hospital, Elzohour, Port-fouad hospitals

\section{B. Target population}

Convenience samplings were selected from available nurses worked in the selected setting as mentioned above it included 99 nurses.

Exclusion criteria:

- Partnership nurses.

- Nurse's students.

C. Tools for Data Collection:

Data was collected by using one tool contains 3 main parts developed by the researchers based on recent related literature review and modificated tool from Registered Nurses' Association of Ontario (2006) and Ayello, 2004to assess the nurse's knowledge and practice toward Braden Scale as follows:

Part I- Sociodemographic data:

It was Contains information related to demographic 
characteristics of the studied nurses as their age, gender, educational class level, occupation and residence.

Part II: Nurse's knowledge regarding Braden scale Questionnaire:

It includes 8 questions to assess the nurse's knowledge related to definition of braden scale, importance of used it, criteria of Braden scale and composition with marks.

Part III: Observational checklist in using braden scale sheet:

It includes6items to assess nurse's practice in application and using of Braden scale criteria, it includes the assessment of sensory perception ability, humidity, ability for doing daily activity, mobility pattern, nutrition, and Friction/shear. which each item takes scores from 1 to 4 except friction /shear takes scores from 1 to 3 and total scores of all items takes 23 which arranged as very high risky patients for pressure ulcer take scores below 9, high risky take 10-12 scores, moderate risk take 13-14 and mild risk take 15-18.

(2) Operational Design:

The operational design includes preparatory phase, content validity, reliability, pilot study and fieldwork.

\section{A. Preparatory Phase:}

It includes reviewing of literature, different studies and theoretical knowledge of various aspects of the problems using books, articles, internet, periodicals and magazines.

$B$. Content Validity:

Validated tools were used from Published sources as mentioned before in tools of data collection.

C. Content Reliability:

Was done through:

\subsection{Pilot Study}

Pilot study was carried out after the development of the tools on $10 \%$ of the nurses to test applicability of the tools then necessary modification were done according to the results of the results of pilot study and expertise opinions. The purpose of pilot study was:

1. To test the applicability of the study tools.

2. To estimate any need for addition in the tool.

Otherwise, these nurses were then excluded from the sample of research work to assure the stability of answers

\subsection{Field Work}

This study was carried out between December, 2014 to February, 2015, a period of 3 months to collect from Saturday until Wednesday; work's selection was done in accordance with the predetermined sample selection criteria. Nurses who met the selection criteria were asked to participate in the study. Each nurse was informed about the purpose of the study. The data were collected throughout three phases of assessment. The first phase (Pre-test phase) was done prior to conducting the educational programme. The second phase (implementation phase) which includes the application of educational programme after divided the sample into groups which group include (10-14) nurses through eight sessions for 8 weeks as one session per week which lasted from 30-45 minutes. The media which used includes: illustrative pictures, real player, video tape and handouts which constructed in a suitable manner for educated and illiterate workers and given for every nurse as a gift. The third phase (post-test phase) was done immediately post implementing educational programme.

\section{(3)Administrative Design:}

\section{Ethical Considerations:}

1. An approval was taken from hospital director and head nurses after brief and comprehensive explanation of the study, its aims and benefits of applying it for nurses and patients.

2. A brief explanation of the purpose and importance of the study was given to the nurses and assured that the obtained information will be confidential and used only the purpose of the study. Confidentiality of the information was assured by the researcher.

(4)Statistical Design:

Collected data was managed, entered then tabulated and analyzed according to the type of each data to realize the study aims.

\section{Scoring System}

The scoring systems for part II of nurse's knowledge was ranged from 0 to 1 scores as zero for No answer and one for yes answer then arranged as total scores of knowledge. Part III are includes an observational checklist to assess nurse's practice regarding using and application of risk assessment Braden scale. It was include 6 items of sensory perception, humidity, activity, mobility, nutrition, and Friction/shear ranged from zero to 2 scores which zero score for not done and 1 score for done incorrect and 2 score for done correctly.

\section{Statistical Analysis}

Data analysis:

Data was collected and entered into a database file. Statistical analysis was performed using the SPSS 19 computer software statistical package. Data was described by summary tables and figures, Chi-2 was used to test the association between two qualitative variables and test / Mcnemar test were used to compared between two or more proportion. Statistical significance was considered at P-value $<0.05$ and highly significance at $\mathrm{P}$-value $<0.00$.

\section{Results}

Figure (1): shows that more than two- third $(78.8 \%)$ of sample were in age group between 50-60 years, while (1\%) of them more than 50 years.

Figure (2): Shows that the most of sample (93.9\%) were married while (1\%) of them where divorced and wood wide.

Figure (3): revealed that $(83.8 \%)$ had diploma level of education while (7.1\%) had university level of education.

Figure (4): shows that more than one quarter $(35.4 \%)$ of nurses worked in Intensive care unit (I.C.U), also (28.3\%) of them worked in medical unit while $(19.2 \%, 17.2 \%)$ worked in orthopedics and coronary care units (C.C.U)respectively.

Table (1): revealed that there are a highly statistically significant difference were found between pre educational 
programme phase and post educational programme phase in relation to total scores of nurse's knowledge of Braden scale as predictive risk assessment of pressure ulcer, $p=(0.001)$.

Table (2):revealed that there are a highly statistically significant difference were found between pre educational programme phase and post educational programme phase in relation to all items of nurse's knowledge of Braden scale criteria and components as predictive risk assessment of pressure ulcer the knowledge of Braden scale criteria and components, $\mathrm{p}=(0.001)$.

Table (3) revealed that there are a highly statistically significant difference were found between pre educational programme phase and post educational programme phase in relation to nurse's total scores of practice of Braden scale as predictive risk assessment of pressure ulcer, $p=(0.001)$.

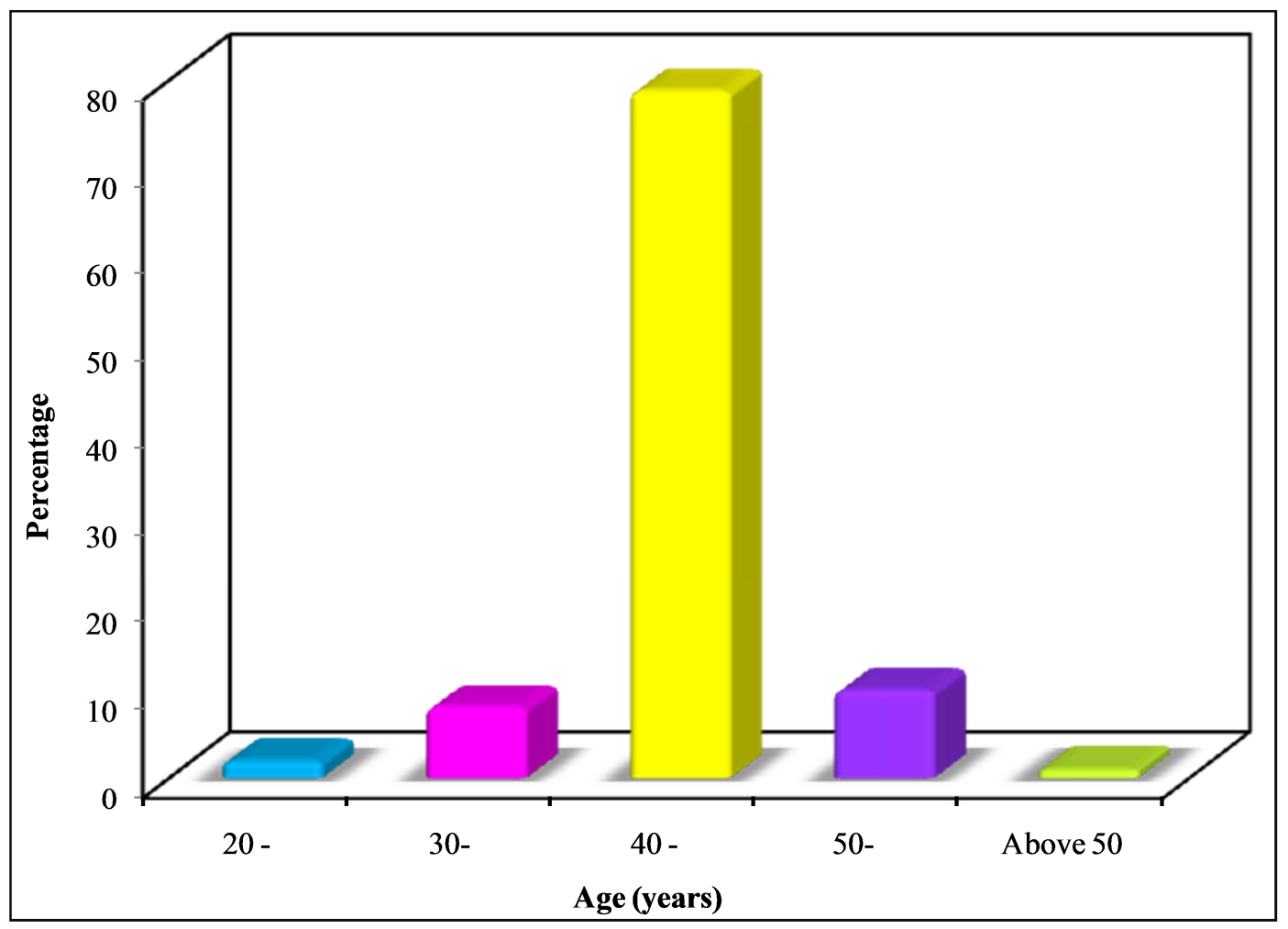

Figure 1. Distribution of the studied cases according to age.

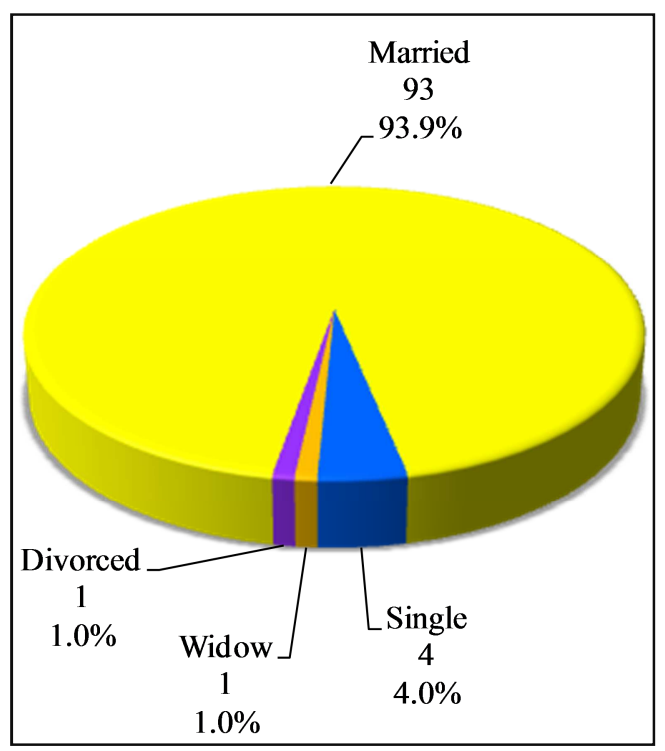

Figure 2. Distribution of the studied cases according to marital status.

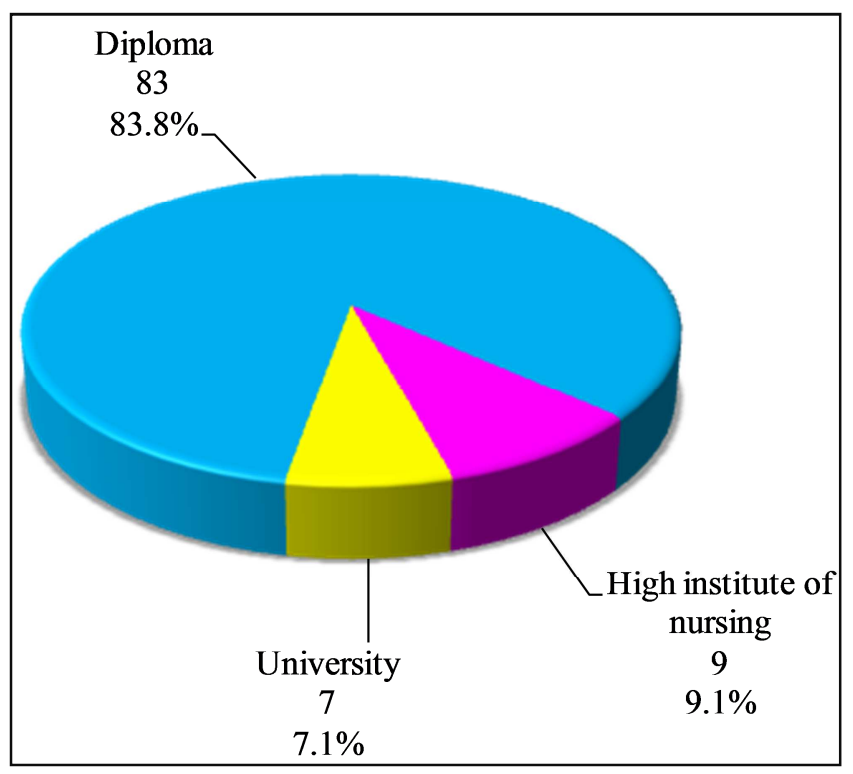

Figure 3. Distribution of the studied cases according to Education. 


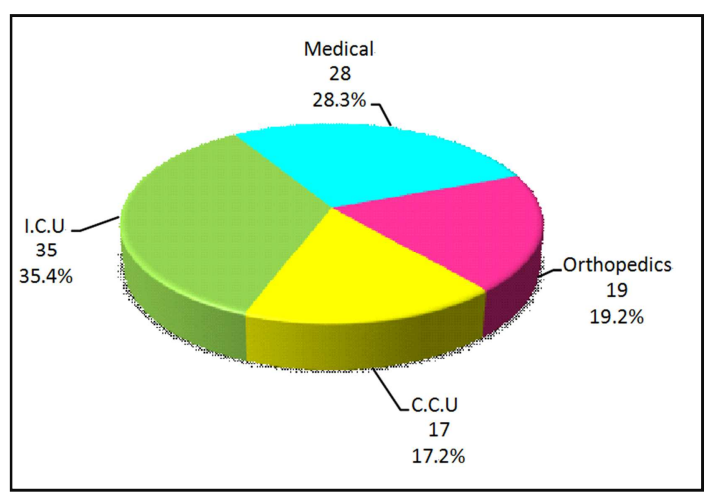

Figure 4. Distribution of the studied cases according to Unit.
Table 1. Comparison between pre and post according to total mean scores of knowledge $(n=99)$.

\begin{tabular}{lllll}
\hline Mean\% score & Pre & Post & t & $\mathbf{p}_{\mathbf{1}}$ \\
\hline Braden Scale & & & & \\
Min. - Max & $0.0-100.0$ & $37.50-100.0$ & & \\
Mean \pm SD & $12.88 \pm 19.92$ & $91.16 \pm 17.97$ & 30.875 & $<0.001^{*}$ \\
Mean \pm SD & $17.93 \pm 24.23$ & $96.46 \pm 9.46$ & & \\
Total knowledge & & & & \\
Min. - Max & $0.0-96.67$ & $56.67 \pm 96.67$ & $6.496^{*}$ & $<0.001^{*}$ \\
Mean \pm SD & $15.22 \pm 18.64$ & $91.01 \pm 10.04$ & & \\
\hline
\end{tabular}

t: Student t-test

*: Statistically significant at $\mathrm{p} \leq 0.05$.

Table 2. Comparison between pre and post according to all items of nurse's knowledge of Braden scale criteria and components $(n=99)$.

\begin{tabular}{|c|c|c|c|c|c|c|}
\hline & \multirow{2}{*}{$\begin{array}{l}\text { Pre } \\
\text { No. }\end{array}$} & \multirow[b]{2}{*}{$\%$} & \multicolumn{2}{|c|}{ Post } & \multirow{2}{*}{$\chi^{2}$} & \multirow[b]{2}{*}{$\mathbf{p}$} \\
\hline & & & No. & $\%$ & & \\
\hline \multicolumn{7}{|l|}{ Are you know Braden scale? } \\
\hline Yes & 17 & 17.2 & 96 & 97.0 & \multirow{2}{*}{$128.654^{*}$} & \multirow{2}{*}{$<0.001^{*}$} \\
\hline No & 82 & 82.8 & 3 & 3.0 & & \\
\hline \multicolumn{7}{|l|}{ Are you known the important of Braden scale? } \\
\hline Yes & 17 & 17.2 & 96 & 97.0 & \multirow{3}{*}{$128.654^{*}$} & \multirow{2}{*}{$<0.001^{*}$} \\
\hline No & 82 & 82.8 & 3 & 3.0 & & \\
\hline \multicolumn{6}{|l|}{ What's the important touse Braden scale } & \\
\hline Helps to ease the movement of the parties & 42 & 42.4 & 4 & 4.0 & \multirow{4}{*}{$124.231^{*}$} & \multirow{4}{*}{$<0.001^{*}$} \\
\hline Helps heal bedsore & 30 & 30.3 & 6 & 6.1 & & \\
\hline Assess the patient $\mathrm{s}$ risk relates to evaluation & 11 & 11.1 & 89 & 89.9 & & \\
\hline I don't know & 16 & 16.2 & 0 & 0.0 & & \\
\hline \multicolumn{7}{|l|}{$\begin{array}{l}\text { How many the criteria for measuring risk } \\
\text { assessment in Braden scale }\end{array}$} \\
\hline 5 & 32 & 32.3 & 3 & 3.0 & \multirow{4}{*}{$140.053^{*}$} & \multirow{4}{*}{$<0.001^{*}$} \\
\hline 4 & 36 & 36.4 & 5 & 5.1 & & \\
\hline 6 & 8 & 8.1 & 91 & 91.9 & & \\
\hline I don't know & 23 & 23.2 & 0 & 0.0 & & \\
\hline \multicolumn{7}{|l|}{ What are the total marks for Braden scale? } \\
\hline 15 & 30 & 30.4 & 4 & 4.0 & \multirow{4}{*}{$109.998^{*}$} & \multirow{4}{*}{$<0.001^{*}$} \\
\hline 20 & 27 & 27.3 & 6 & 6.1 & & \\
\hline 23 & 16 & 16.2 & 89 & 89.9 & & \\
\hline I don’t know & 26 & 26.3 & 0 & 0.0 & & \\
\hline \multicolumn{7}{|l|}{ All Braden scale items take the same marks } \\
\hline Nutrition & 39 & 39.4 & 3 & 3.0 & \multirow{4}{*}{$127.456^{*}$} & \multirow{4}{*}{$<0.001^{*}$} \\
\hline Mobility & 36 & 36.4 & 7 & 7.1 & & \\
\hline Itching & 10 & 10.1 & 89 & 89.9 & & \\
\hline I don’t know & 14 & 14.1 & 0 & 0.0 & & \\
\hline If the patient takes $13-14$ marks it means -- & & & & & & \\
\hline Severe risk & 35 & 35.4 & 1 & 1.0 & & \\
\hline Moderate risk & 15 & 15.2 & 90 & 90.9 & $118941^{*}$ & $<0001^{*}$ \\
\hline No risk & 23 & 23.2 & 8 & 8.1 & 118.941 & $<0.001$ \\
\hline I don’t know & 26 & 26.3 & 0 & 0.0 & & \\
\hline Braden scale components includes ------- & & & & & & \\
\hline Perception & 6 & 6.1 & 2 & 2.0 & & \\
\hline Humidity & 7 & 7.1 & 1 & 1.0 & & \\
\hline Activity & 9 & 9.1 & 1 & 1.0 & & \\
\hline Movement & 16 & 16.2 & 4 & 4.0 & & \\
\hline Nutrition & 13 & 13.1 & 3 & 3.0 & $135.122^{*}$ & ${ }^{\mathrm{MC}} \mathrm{p}<0.001^{*}$ \\
\hline Itching & 4 & 4.0 & 5 & 5.1 & & \\
\hline All the above & 8 & 8.1 & 82 & 82.8 & & \\
\hline Nothing & 20 & 20.2 & 0 & 0.0 & & \\
\hline I don't know & 16 & 16.2 & 1 & 1.0 & & \\
\hline
\end{tabular}

$\chi^{2}$ : Chi square test.

$*$ : Statistically significant at $\mathrm{p} \leq 0.05$.

MC: Monte Carlo test. 
Table 3. Comparison between pre and post regarding total nurse's practice of Braden scale.

\begin{tabular}{|c|c|c|c|c|c|c|}
\hline Total items of practice & No. items & Scores & Pre & Post & t & $\mathbf{p}_{1}$ \\
\hline $\begin{array}{l}\text { Total score } \\
\text { Min. }- \text { Max } \\
\text { Mean } \pm \text { SD } \\
\text { Mean } \% \text { score } \\
\text { Min. }- \text { Max } \\
\text { Mean } \pm \text { SD }\end{array}$ & 4 & $0-8$ & $\begin{array}{l}0.0-8.0 \\
3.21 \pm 2.29 \\
0.0-100.0 \\
40.15 \pm 28.59\end{array}$ & $\begin{array}{l}4.0-8.0 \\
7.95 \pm 0.41 \\
50.0-100.0 \\
99.37 \pm 5.17\end{array}$ & $20.885^{*}$ & $<0.001^{*}$ \\
\hline
\end{tabular}

$\mathrm{t}$ : Student t-test.

*: Statistically significant at $\mathrm{p} \leq 0.05$.

\section{Discussion}

Nursing team members are responsible for direct and continuous care related to PU prevention and treatment. For nursing to achieve quality care, its practiceneeds to be based on the best evidence regarding the theme. Knowledge about this evidence on PU should be part of all nursing professionals' knowledge base. Education programs should focus not only on prevention and treatment interventions and ulcer characteristics, but also on the legal implications of correct patient file documentation (Miyazaki and et al,2010)

Regarding sociodemographic characteristics of the study sample, the present study revealed that more than two- third of sample were in age group between 50-60 years, while (1\%) of them more than 50 years. also, that the most of sample were married while $(1 \%)$ of them where divorced and wood wide and more than three - quarter of them had diploma level of education while (7.1\%) had university level of education. In addition to, more than one quarter of nurses worked in burn unit, also $(28.3 \%)$ of them worked in medical unit while $(19.2 \%, 17.2 \%)$ worked in orthopedics and neurological units respectively.

Regarding nurse's knowledge towards Braden scale the present study revealed that there are a highly statistically significant difference was found between pre educational programme phase and post educational programme phase in relation to nurse's total scores of knowledge of Braden scale as predictive risk assessment of pressure ulcer. This finding goes in the same line with Mohammed et al, 2003 who mentioned that Quality improvement can be used to obtain information about the effectiveness of nursing care and the need for additional education or policy changes. If deficiencies are identified, in service training can focus on those specific areas. Knowledgeable nurses and ongoing updated in service education and training are essential if measurable improvements are to be achieved. Therefore, the present study will be carried out in an attempt to provide nurses with a training program that includes the needed knowledge and skills about how to identify, prevent and manage bedsores for immobilized patients and to investigate the impact of that training program on nurses' knowledge and practices as well as bedsores patients' condition.

In a recent study carried out in New Zealand, the authors created a knowledge test on PU prevention, based on international guidelines and involving eight international experts on the theme. Using a modified Delphi technique and electronic communication, they reached a consensus on the questions' contents and on $76 \%$ of correct answers as a minimum competency level for nurses to pass the test. The test was used to assess the impact of an educative program, including an oral presentation with slides and discussion, taking approximately three hours, offered to ICU nurses. Measurements took place before, two and 20 weeks after the course. The nurses answered $84 \%$ of questions correctly before the course, $89 \%$ on the first assessment two weeks after and $85 \%$ on the second assessment after 20 weeks. Differences between results before and two weeks after the event were statistically significant $(p=0.003)$, but no difference was found when comparing the same subjects' results before and 20 weeks after the event. (Miyazaki et al, 2010). Additionally, It is important to highlight that the version of the Braden scale adopted in this study has low sensitivity but high specificity. However, the high specificity of the instrument, coupled with simultaneous use of digital photos, ensures that the data found faithfully portray the situation of the ICU of the institution evaluated in relation to pressure ulcers. (De araujo et al, 2012)

Concerning nurse's practice of Braden scale, the present study revealed that there is a highly statistically significant difference was found between pre educational programme phase and post educational programme phase in relation to nurse's total scores of practice of Braden scale as predictive risk assessment of pressure ulcer. This result is consistent with the findings of Mohamed and Weheida, 2015who reported improving the nurses' knowledge and skills after implementation of in service program to pressure ulcer. On the other hand, preventive interventions (nutritional supplementation; repositioning; pads and dressings; lotions, creams, and cleansers) for patients at high risk for pressure ulcer was more effective than usual care in preventing pressure ulcer.

From the forgoing discussion, prevention of pressure ulcer through using Braden scale as predictive risk assessment tool is critically significant factor in the continued health and wellbeing of the patient. Prevention is generally considered the most effective way to confront the occurrence of pressure ulcer. It can improve patient outcomes and reduce health service resource use and costs as well as human suffering. Prevention involves a variety of issues, including identification of those deemed to be at risk of developing pressure ulcers, appropriateness of care and increase awareness of the preventive measures of pressure ulcer. Involvement of caregivers in pressure ulcer prevention can ensure both quality 
care and reduce costs. (Alhosis et al, 2012)

Furthermore, almost all nurses working in the ICU of Traumaunit and / or Neurology Department of Assiut University Hospital are in great need to develop and maintain their knowledge and skills in relation to the care for immobilized patients as regards the identification, prevention and management of bed sores. Based on their results of the implementation phase, it has been observed that nurses' age mostly ranged from 20 to 25 years with a mean duration of experience of $25.4 \pm 11.6$ months. Results of the analysis before program implementation (pretest) showed very low levels of knowledge and practices as regards the identification, prevention and management of bed sores. This might be related to the lack of scientific preparation of nurses.(Mohamed et al, 2003)

Since the effectiveness of the Braden scale as a pressureulcer risk-assessment tool appears to be supported by research, it was decided that the next stage of the project was to pilot its use for one month. A medical ward caring for older people was selected as its nurses generally accepted that pressure-area care was a priority. (Stevenson, 2004)

\section{Conclusion \& Recommendations}

In conclusion, this study found that implementation of educational program is highly effective in improving knowledge and practice of nurses in critical units in comparing with the knowledge and practice pre educational programme implementation. Based on the findings of the current study, it is recommended that further research is needed to consider the routine use and regular revision of pressure ulcer risk assessment sheet should be encouraged, obstacles with regard to the implementation of pressure ulcer preventive measures should be recognized and addressed to achieve a change in practice and there is a need to plan an in service training program for the nursing staff, which is necessary for the continuously advancing care for patients in this area.

\section{References}

[1] Hussain, S. (2009): "A study to determine the effectiveness of structured teaching programme on knowledge regarding prevention of pressure ulcer among immobilized orthopedic patients in selected hospitals at Gulbarga ", $1^{\text {st }}$ year M.Sc Nursing H.K.E.S, College of Nursing, Basveshwar hospital, campus Gulbarga, Karnataka. P.3.

[2] Vangberg, H. B. (2008): Perceived Safety in Mining: A development of the (Vangberg-Eisemann) Perceived Safety Scale (VEPSS), published master thesis, university of Tromsø, p.8-10.
[3] Registered Nurses' Association of Ontario (2006). Part B: Educational Workshop for Unregulated Care Providers: Assessment and Management of Pressure Ulcers. Toronto, Canada: Registered Nurses' Association of Ontario.

[4] Ayello, E. A. (2004): Predicting pressure ulcer risk. In: Boltz M, series ed. Try This: Best Practices in Nursing Care to Older Adults. 1, (5):p. 4. The Hartford institute for Geriatric Nursing. www.hartfordign.org.

[5] Leathey E. Smith, L.E; Forsythe, L; Axley, L; Matthew, T. (2014): Future of healing: creating a pressure ulcer prevention and management programin a long -term care setting, published doctorate thesis in nursing practice, Capella University.

[6] Alhosis, K. F; Qalawa, S.A and Abd El-Moneem, D.S (2012): Effect of Designed Pressure Ulcer Prevention Program on Caregivers' Knowledge of Immobilized Patients. J Am Sci 2012; 8(12):939-948]. (ISSN: 1545-1003). http://www.jofamericanscience.org. 130.

[7] Chopra, J.I. (2004). "Nurses role in the management and prevention of pressure ulcer". Nursing Journal of India. 19(3):123-29.

[8] Thomas. C. (2009): An expermintal study to evaluate the effectiveness of local application of insulin on pressure ulcer among the bed ridden patients, $1^{\text {st }}$ year YEAR M.SC nursing, Cauvery college of nursing, Mysore: p.3.

[9] Mary D. Gordon, M.D; Gottschlich, M.M; Helvig, E.I; Marvin, J.A; Reginald L. Richard, R.L.(2004): Review of Evidenced-Based Practice for the Prevention of Pressure Sores in Burn Patients, Journal of Burn Care \& Rehabilitation, 25, (5):p.388.

[10] Miyazaki, M.Y; Caliri, M.H; dos Santos, C.P.(2010): Knowledge on Pressure Ulcer Prevention Among Nursing Professionals, Rev. Latino-Am. Enfermagem, 18(6):1205 www.eerp.usp.br/rlae

[11] De Araújo, T.M; de Araújo, M. F; Caetano, J.A. (2012): Using the Braden Scale and photographs to assess pressure ulcer risk, Rev Esc Enferm USP, 46(4):859www.ee.usp.br/reeusp/.

[12] National institute for health and care Excellence. (2014): Pressure ulcers: prevention and management of pressure ulcers, NICE clinical guideline, April, 179.

[13] Mohamed, S.A; Weheida, S.M.(2015): Effects of implementing educational program about pressure ulcer control on nurses' knowledge and safety of immobilized patients, Journal of Nursing Education and Practice, 5, (3):p.11.

[14] Mohamed, Z.M; Mohamed, W.M; M.A El-Sonbaty. (2003): impact of an -in service training programme on bed sores identification, prevention and management among immobilized patient s, Ass. Univ. Bull. Environ. Res. 6 (1):p.135.

[15] Tracey Stevenson.(2004): Improving policy and practice in the prevention of pressure ulcers, clinical care and research journal, 100 (9):p. 2cited in www.nursingtimes.ne 